\section{References}

1. Chin ET, Huynh BQ, Chapman LAC, et al. Frequency of routine testing for coronavirus disease 2019 (COVID-19) in high-risk healthcare environments to reduce outbreaks. Clin Infect Dis 2020. doi: 10.1093/cid/ciaa1383.

2. Shenoy ES, Weber DJ. Routine surveillance of asymptomatic healthcare personnel for severe acute respiratory coronavirus virus 2 (SARS-CoV-2): not a prevention strategy. Infect Control Hosp Epidemiol 2021;42:592-597.

3. Chow A, Htun HL, Kyaw WM, Lee LT, Ang B. Asymptomatic health-care worker screening during the COVID-19 pandemic. Lancet 2020;396: 1393-1394.

4. Htun HL, Lim DW, Kyaw WM, et al. Responding to the COVID-19 outbreak in Singapore: staff protection and staff temperature and sickness surveillance systems. Clin Infect Dis 2020;71:1947-1952.
5. Wang Y, Tan JK, Tay MZ, et al. Dancing with COVID-19 after the hammer is lifted: enhancing healthcare worker surveillance. J Infect 2020;81(6):e13-e15.

6. Kyaw WM, Hein AA, Zhang ZX, et al. Healthcare worker acute respiratory illness cluster in 2020: could it be from COVID-19? Infect Control Hosp Epidemiol 2020. doi: 10.1017/ice.2020.364.

7. Lim DW, Htun HL, Wang Y, et al. Healthcare workers as 'canaries' for acute respiratory infections and pathogens during the COVID-19 pandemic. $J$ Hosp Infect 2021;112:119-120.

8. Sim D, Kok X. 'Far from out of the woods': how a COVID-19 variant put Singapore back in defensive mode. South China Morning Post website. https:/www.scmp.com/week-asia/health-environment/article/3134497/farout-woods-how-covid-19-variant-put-singapore-back. Published May 23, 2021. Accessed May 23, 2021.

\title{
Promoting coronavirus disease 2019 (COVID-19) vaccination: Do we need to reframe how we present risk?
}

\author{
Michelle Doll MD, MPH ${ }^{1}$, Jeanine P. D. Guidry $\mathrm{PhD}^{2}$, Rachel Pryor RN, MPH${ }^{1}$, Arthur L. Kellermann MD, MPH ${ }^{1}$ and \\ Michael P. Stevens MD, MPH ${ }^{1}$ \\ ${ }^{1}$ Virginia Commonwealth University Health System, Richmond, Virginia and ${ }^{2}$ Virginia Commonwealth University, Richmond Virginia
}

To the Editor-Although impressive progress has been made in vaccinating the US population against coronavirus disease 2019 (COVID-19), the country has not yet reached the level of uptake needed to assure the added benefit of "herd immunity." 1 Equally if not more concerning, substantial subgroups of the population remain skeptical if not overtly resistant to vaccination. To convince as many of these individuals as possible to change their mind, it is imperative that we communicate the benefits of vaccination in more meaningful ways.

Recently we reported how Virginia Commonwealth University Medical Center in Richmond swiftly contained an outbreak of employee infections that coincided with the "third wave" of COVID-19 that hit Virginia between December 2020 to January 2021. ${ }^{1}$ During a single week (December 13-19), 134 of 13,346 employees, or $\sim 1 \%$ of our entire workforce, became infected with severe acute respiratory coronavirus virus 2 (SARS-CoV-2). Fortunately, we received our first doses of vaccine that same week and began vaccinating employees on December 16. The campaign that followed, along with a bundle of intensified infection-prevention measures, produced a 10 -fold reduction in healthcare worker (HCW) infections (down to $0.1 \%$ ) by January 31). Based on our local experience, we calculated that getting vaccinated against COVID-19 reduces a VCU Health employee's odds of getting infected by $98 \% .^{2}$

A potentially more compelling way to express this beneficial effect is to quantify the relative risk, compared to vaccinated colleagues, that an unvaccinated HCW will become infected with the virus that causes COVID-19. As of May 3, 2021, that risk is 27.9 times greater in unvaccinated HCWs at VCU Health.

\footnotetext{
Author for correspondence: Michelle Doll, E-mail: michelle.doll@vcuhealth.org Cite this article: Doll M, et al. (2022). Promoting coronavirus disease 2019 (COVID-19) vaccination: Do we need to reframe how we present risk?. Infection Control \& Hospital Epidemiology, 43: 1530, https://doi.org/10.1017/ice.2021.302
}

A recent study from Israel reported the real-world effectiveness of the Pfizer-BioNTech mRNA vaccine BNT162b2. The incidence rate of SARS-CoV-2 per 100,000 person days was 91.5 in unvaccinated people versus 3.1 in fully vaccinated people-an effectiveness rate of 95.3 percent. $^{3}$ In other words, unvaccinated people were 29.5 times more likely to become infected than those who were vaccinated.

Rather than focus on the risks of vaccination, which is tiny by comparison, the public would be better served by focusing on the far larger and more severe risk incurred by those who forego or decline repeated opportunities to be vaccinated.

If VCU Health data are representative of the general public, the risk that an unvaccinated adult will become infected with the virus that has killed $>600,000$ Americans and $>3.4$ million people worldwide, is $\sim 28$ times higher than those who accept vaccination. This way of framing risk may be of value to infection prevention specialists involved in COVID-19 vaccine messaging campaigns.

\section{Acknowledgments.}

Financial support. No financial support was provided relevant to this article.

Conflicts of interest. All authors report no conflicts of interest relevant to this article.

\section{References}

1. Randolph HE, Barreiro LB. Herd immunity: understanding COVID-19. Immunity 2020;52:737-741.

2. Pryor R, Cooper K, Britton A, et al. Riding the third wave: how an academic medical center reduced COVID-19 infections in healthcare workers. $N$ Engl J Med Catalyst 2021. doi: 10.1056/CAT.21.0060.

3. Haas EJ, Angulo FJ, McLaughlin JM, et al. Impact and effectiveness of mRNA BNT162b2 vaccine against SARS-CoV-2 infections and COVID-19 cases, hospitalisations, and deaths following a nationwide vaccination campaign in Israel: an observational study using national surveillance data. Lancet 2021;397:1819-1829. 